\title{
Lessons learned on the planning and execution of technology innovation projects with academic partnership: aerospace industry case study
}

\author{
Claudiano Sales Araujo \\ Brazilian Aeronautics Company \\ email: claudiano@dr.com
}

\begin{abstract}
This article presents and discusses a set of lessons learned by a large industry in the Brazilian aerospace sector on the planning and execution of high risk, high-technology content innovation projects (technology development) in partnership with academic institutions. It summarizes the key points that the project managers involved in this study regarded as crucial to the successful planning and execution of this particular type of project. Even though most of the points discussed in the article are already covered in the present body of literature on project management, these contributions are too general in their approaches and do not take proper consideration of the specific aspects or characteristics of the projects that are the focus of this study. It is suggested that the lessons discussed in the article, in spite of being based on a research carried out in just one company, be used as a reference not only by other engaged companies that need to generate practical results for projects being executed in partnership with academia, but also for researchers interested in advanced studies in the area of project management.
\end{abstract}

Keywords: lessons learned, open innovation, project management in partnership.

\section{Introduction}

From one side products are getting more complex, with a larger degree of integration, more market pressure, an aggressive competitive landscape, new entrants, etc, with no evidence of any kind that this scenery will ameliorate in the upcoming years or decades. To keep competitive is a matter of life or death. In this path many new management strategies, approaches and solutions are developed and continually implemented into the practice of industry, in special by companies involved with high-technology products, due to the fast moving pace of these sectors.

Among these new practices and approaches being progressively more adopted by companies engaged in the development of high-tech content products we can mention the adoption of partnerships, not only for the development of new products (CAETANO et al., 2011), but also as a mechanism to allow for the rapid expansion of their technology domain as a basis for their long term product development and market strategies.

Partnerships can be made with other companies, research institutions, or even through the formation of networks involving many companies and research institutions. Partnership strategies have been largely discussed from within the knowledge area generally denominated Open Innovation (e.g., CHESBROUGH, 2003; COOPER, 2008).

Complementary, government entities and research support organizations, either in Brazil, or outside, have been increasingly and consistently supported partnership initiatives, with an emphasis on projects involving cooperation among research institutions and industry. A summary of the innovation public policies in the USA, Europe and Brazil is discussed, for instance, in Balaguer et al. (2000).

The remaining problem is how to plan and execute these projects with success. Indeed, if successful execution of these projects is not accomplished, the virtuous cycle never closes, and the expected results and benefits are never achieved.

It is possible to say that, even though successful planning and execution of product development projects have been discussed in the literature (e.g., PROJECT, 2008; KERZNER, 2002; DINSMORE, 2003; FRAME, 1995; SANTOS; CARVALHO, 2006), most of these contributions are based on, and directed to, development projects involving well a know object under low degree of uncertainty (development of a bridge, for instance). Very few contributions have be directed to the management of high-tech, high-risk, high-uncertainty partnership based development projects, and even less if the object of the development effort is a new, pre-competitive, technology instead of a product (AJAMIAN; KOEN, 2002; COOPER, 2007). 
In fact, the management of this type of project is not trivial, being quite different, in many ways, from the management of more traditional projects. Lack of ability and/or proper methodologies to manage these projects is frequently pointed out as one important cause for the poor degree of success observed in the practice of these projects (e.g., CAETANO et al., 2011; MORRIS; PINTO, 2007). Indeed, for projects of this nature, many of the methods, rules and fundaments well disseminated for the management of traditional projects appear to be totally out of context or proportion, with low general applicability, as reported by the project managers where the study described in this article took place. Among the characteristics that make these projects so different from more traditional projects, we can mention:

- High degree of scope and/or object uncertainty, as well as the strategies and ways to achieve the goals proposed for these projects;

- Complexity of the risks associated to these uncertainties, including a always higher than recommended amount of technical risks;

- Use of government funding, which brings economic benefits to the project, but also many additional difficulties, in special the increase of bureaucracy and restrictions that the project manager will have to deal with along the project, as exploited in Section 4;

- Use of small, high-tech teams, where there is no availability of resources and/or spare time to the team to implement any complete set of traditional project management methodologies;

- Pre-competive nature of these projects. In general the technologies being developed are not directly associated to any specific product, as described in Section 2;

- Difficulties to demonstrate to top management the monetary return of investment in these projects, as their results will only become concrete, and therefore measurable, many years later, when the new products developed by the company incorporate the technology developed by the project;

- High degree of technical specialization necessary to the teams involved in these projects.

\section{Methodology}

In order to investigate the best approach to manage these projects, a study was conducted in a large aircraft manufacturing company in Brazil. This study investigated the practice, experiences and lessons learned in the planning and execution of high-risk, technology development (pre-competitive) projects conducted by the company in partnership with the academia.

The company where the work was developed has about 14 years of experience carrying out this specific type of project in partnership with academia, with varied degree of success. Ten (10) project managers working from within the company's technology development program were invited, participated and contributed to the study. The study was carried out in the form of free face-to-face interviews where the participants were asked to describe their experiences with these projects, and the lessons (good and bad) they learned from them. The article summarizes the key points, aspects and issues raised by this sample of project managers, with a focus on what they considered to be the most critical for the success of these projects.

\section{Types of projects and scope of applicability of the presented lessons}

This section clarifies the type of projects discussed in the article, thus, forming the scope of applicability of the results presented in Section 5.

Most of the projects carried out by aerospace manufacturing companies, as part of their core business, are related to the development of new or improved versions of airplanes. These "product development" projects can have as object the delivery of new airplanes intended to commercial, executive or defense markets. They are mostly very large projects, always involving hundreds of engineers, different partners and suppliers working from various countries, budgets in the excess of US\$ $1 \mathrm{Bi}$, and a time frame of around 5 years or more (ARAUJO; CRUZ, 2000).

These projects are generally named and treated by manufacturing companies in the aeronautic sector as "programs". They have their own management structure, with traditional project management processes and methods generally implemented to their full extend, very near to what is suggested by traditional project management theory (e. g., PROJECT..., 2008). In relation to the graphic shown in the Figure 1, which classifies projects according to two axis, "scope complexity" and "technical uncertainty" (after SHENHAR, 2000), we can say that the development of new or improved products, within this industgrial sector, can be described as having medium to low degree of technical uncertainty and high degree of scope complexity.

At the other end of the spectrum of Figure 1, we find those small-sized projects, typically associated with low degree of technical uncertainty and scope complexity. Here we will find the large internal portfolio of process improvement projects, IT and infrastructure projects, among others.

Apart from the two groups of projects described above, we will also find a very particular portfolio of projects, with very high degree of technical uncertainty and low to medium degree of scope complexity. This portfolio of projects composes what the company calls the "technology development program", and is the focus of this article. 
It has been more than 14 Years since the company is formally engaged in structuring, planning and executing this particular type of projects. They vary from small projects, involving less than one dozen of specialists (including those from academia), and a budget smaller than US $\$ 500.000,00$, to larger projects, involving dozens of research institutions, companies, and budgets larger than US\$ 10 Million.

One important aspect to notice is that the technology development program at this company has a precompetitive nature. That is, the technologies developed from these projects are not immediately associated to any specific product or ongoing product development effort. Figure 2, based on Alves (2009), describes the difference

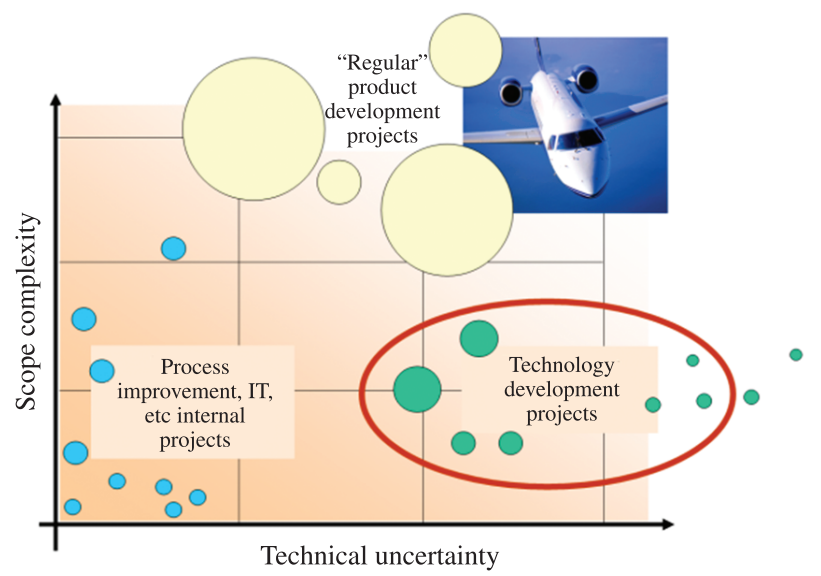

Figure 1. Distribution of projects in the context of the selected company: Scope complexity vs tecnical uncertanty (Based on SHENHAR, 2000). between pre-competitive projects (internally named "technology development" projects) from competitive product development projects (internally named "product development" projects).

Technology development projects are basically about attaining a certain readiness level (TRL level) over a given technology, object of the project. This technology will, eventually, be incorporated into the future products to be developed by the company, according to their adequacy to the strategies or requirements for these products. As an example of pre-competitive technology development projects we could mention the development of aeronautical new materials, fly-by-wire technologies, new manufacturing techniques, aeronautic applications of nano-technologies, augmented reality, among many others.

The execution strategy for these projects varies, depending on the situation (Figure 3). For instance, if the project involves new technologies that are regarded as confidential or secret to the company, or that the company understands that should not be exposed to the competition for strategic reasons, or when the timing is crucial and the necessary competences are available, the company may choose to carry out the project internally (i.e., with no partnership).

In some cases it can be a better approach to obtain the technology throughout the direct acquisition of services from specialized consultant companies or from companies that detain the technology of interest (Figure 3, case 2). In some other cases the full acquisition of the company which detains the technology can also be considered.

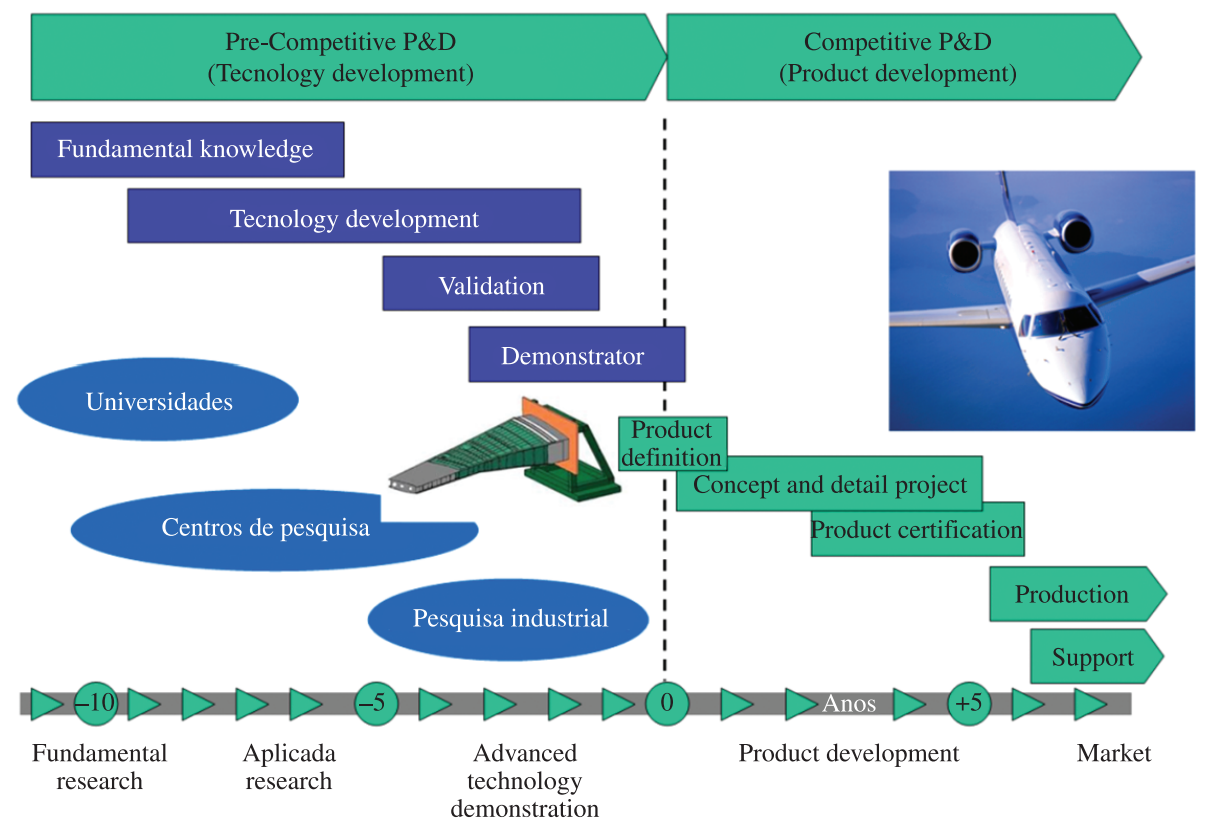

Figure 2. Pre-Competitive and Competitive P\&D - Aeronautic Industry (adapted from ALVES, 2009). 

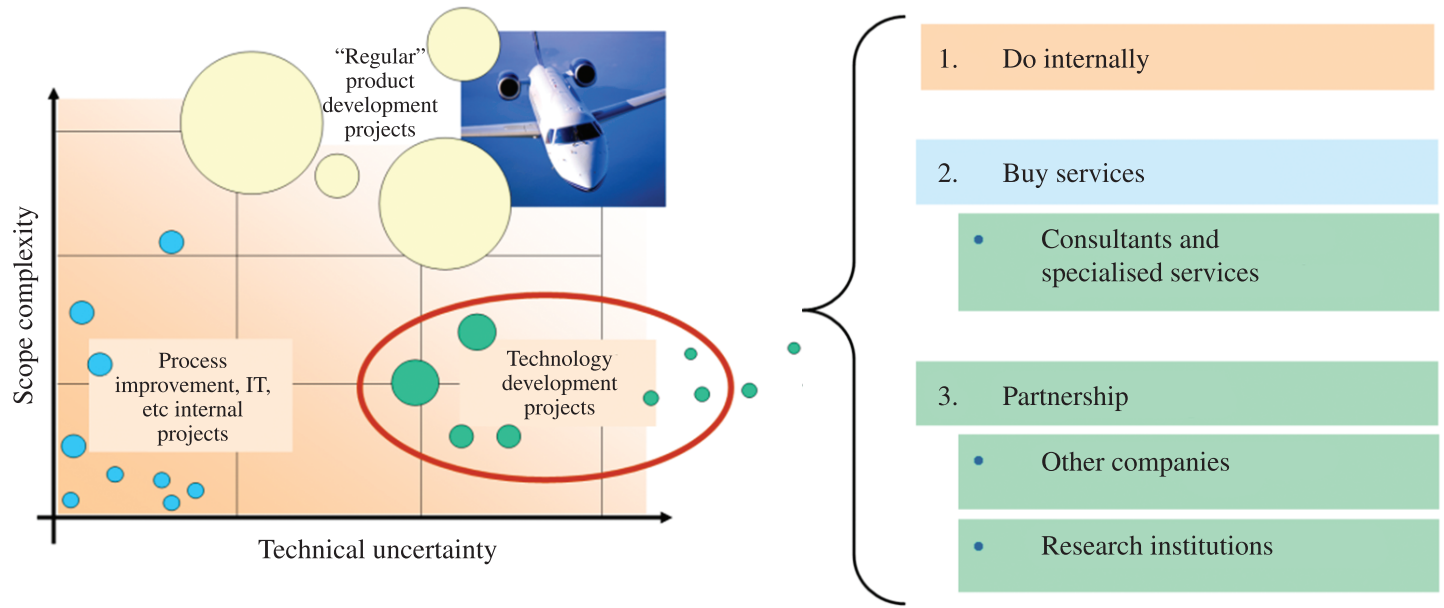

Figure 3. Execution of technology development project can use different strategies.

Finally the strategy can involve developing the project in partnership with other companies, or with research institutions (academia, research centers, etc). The lessons learned specifically with the projects developed in partnership with research institutions compose the focus of this article.

\section{Projects with academic partnership - advantages and disadvantages}

The proliferation of the strategy of executing high-risk, high-uncertainty, technology development projects in partnership with academic institutions is a relatively new practice at least in the Brazilian context. As expected, the opinions and perceptions of the advantages and disadvantages of this type of venture vary.

Bellow is a summarized list of reasons why the managers interviewed in this study believe that developing these projects with the partnership of academic and research institutions is a good choice.

- "Because results are consistent". Indeed, more than $90 \%$ of the technology development projects conducted by this company in partnership with academic institutions were completed to the last deliverable, and the results have been already implemented by the company. The general satisfaction with the results from these projects are described as "good" or "very-good" by most of the interviewed managers;

- "Degree of specialization needed to the project is very often not available in the company". The execution of these project in partnership with high-level research institutions allows for the quick aggregation of knowledge and specialization, essential for the sucess of the project, but not available in the company, specially the cases of incipient technologies;
- Access to the network of the involved researchers;

- Very often some of the Master and PhD students involved in these projects are hired by the company after the project is completed, which helps to quickly incorporate to the ranks of the company the specialized personal necessary for the carry on the activities involved in the implementation of the technology into the future products of the company;

- "It is financially sound", in special thanks to the funding provided by government agencies such as FINEP and FAPESP, even though there is always a heavy financial counterpart that the company needs to put into the project;

- "Working in partnership with academia is neither more or less difficult than working in partnership with other companies". Thus, if the difficulty is the same, working with academia can be a good choice, in many situations, given the extra gains of this type of approach;

- Contribution to the promotion of research that brings value not only to the company, but also for the involved researchers and institutions - Mutual benefits;

- Access to specialized laboratories available at the involved research institutions, and that may not be available in the company;

- Contribution to the creation of research groups in areas that are common interest to the industry and the academia.

Still from the point of view of the interviewed researchers, the following points represent some of the difficulties found for the successful execution of these propjets with academic partnership:

- "We can't wait results for tomorrow". "Research institutions appear to work in a clocking a little bit different from us". It is a fact that it not always 
possible to conciliate the urgency of the business world with the general speed practiced by academia. This should be taken into consideration when selecting which opportunities should be better executed in partnership with academia, and which are not (see Section 5.1.1);

- There has been lots of cases of key Master Students abandoning these projects before completion, which always causes a major impact on the project schedule. It is an important attention point, as it is considered one typical root cause for many of the cases of long delays in these projects;

- Difficulties and long delays in the conclusion of negotiations involving intellectual property rights of the potential results from these projects;

- Long delays in the processes involving the approval and authorizations for initiation of the projects mostly caused by the excess of laws, normative instructions, regulations, etc from the involved research foundations and/or the funding organizations. This is regarded as one of the most important aspects that very often led the company to follow other execution strategies instead of using partnership with research institutions.

\section{Results: lessons learned and considerations}

The gathered lessons were grouped into 10 interest areas, for better understanding.

\subsection{Group of lessons \#1: project execution strategy}

\subsubsection{Electing the projects to be developed with academia in partnership is a key decision.}

Selecting to develop the project in partnership with academic institutions is indeed not often the best strategy. The experience of the company were the work was conducted shows that in many occasions, and even disregarding the availability of potential funding and interested academic partners, the best approach the best approach is to carry the project without the participation of research institutions. The technology application time frame, for instance, is a key variable in this decision. The more urgent the need for the domain over the technology, the less the odds that developing in partnership with academia will be the best choice. Need for secrecy will be another relevant criteria in this decision.

\subsection{2 "Avoid tentaption!"}

The fact that there has been an increasing in the availability of funding from government agencies does not mean that a company will have the conditions to embrace all of these opportunities! "It is often best to carry out a few projects very well, than to try to embrace the world".

A good analysis of internal work load and capacity is crucial before embarking in new projects of this nature. Further, this type of analysis should carefully consider the specificspecialization necessary for the development of the projectopportunities being analyzed. Along this process the plannershould keep in mind that high-risk, technology developmentprojects are different from traditional product developmentprojects, as discussed in Section 1 of this article.

\subsection{3 "Whenever possible, avoid large projects, involving many institutions, and long duration"!}

In the experience of the interviewed project managers, small, well contained projects, appear to work much better then large projects, involving dozens of institutions, and schedules of 3 or more years. Many reasons support this point. First, it is easier to obtain internal engagement of critical resources for a short period of time than for a longer time, say, more than 2 or 3 years. Second, results are more clearly perceived when projects are contained into short periods (less than 2 years). Financial domain over the project budget is also easier, as budget is easier to secure and control for one or two years than for 3 or more years.

On the other hand, large projects, involving many different organizations are always difficult to put together in first place, as they demand lots of negotiations with different partners, each with its own rules, needs, procedures, expectations, interests, etc. Aligning and maintaining a large team, engaged and motivate, working from different locations for a long period of time is always also a very difficult task, especially in case of projects involving high levels of uncertainty and innovation.

\subsection{Group of lessons \#2: choice of the academic partner}

\subsubsection{Careful consideration of the motivation and real} interests of the researchers in the project subject is the key most important aspect in the choice of the academic partner

Selection of the academic team must go beyond the analysis of classical criteria such as their institution or group's name and/or official productivity rankings. Indeed, the experience from the company appear to fully support the view advocated by J. Paap (e.g., PAAP, 2006) who says that "a partnership with a researcher that is truly motivated and interested in the project, even if he/she belongs to a less reputable institution, is often a much better decision than involving a very famous researcher, from a top university, who is not truly interested in the project". 


\subsection{Group of lessons \#3: project alignment and planning}

\subsubsection{The project plan should be integrated!}

Even though the word "integration" has been used and abused along the years by those writing from the project management arena, the real implementation of its meaning has been vastly neglected by those who should put it in the practice of planning new projects for this company. Integration, during the planning stage of a project, means inviting and involving representatives from all sides of the project scope into the elaboration of the project plan.

A specific method, internally named " $1+15$ day project planning", was devised and has been applied with success for this intend. For this, a 1 day workshop is conducted with the participation of all of the project stakeholders, where the various aspects, understandings and alignments of the project is discussed and a consensus is reached for each key aspect of the project (technical, budget, scope, goals, premises and risks). According to participants, "it is surprising the amount of differences and misalignments that is removed during this one-day workshop". After the workshop the project planning team will have 15 more days to detail each aspect of the project plan.

\subsubsection{Apply wave planning techniques}

Complimentary to the former lesson (5.3.1), and also considering what was discussed in the Introduction to this article, the most differential characteristic of this type of project is its high degree of uncertainty. Thus, instead of wasting a lot of time and energy trying to plan to detail the whole project at its onset, it is a better approach to build, with the participation of all of the involved parties, a macro plan (master phase plan) of the project, and to concentrate to plan in detail each stage of the project at the time, as illustrated in Figure 4. This is called wave-planning, is has been described by authors such as Cooper, 2008.

In this chart, detail planning of stage 2, for instance, is only carried out after stage one of the project is near to its end. In this way full consideration of the findings and results from stage one can be implemented in the planning of stage 2 .

\subsection{3 "Deliverables, deliverables and deliverables"!!!!}

The planning, control and overall management mindset for this type of project should be done based on project deliverables. This is opposed to more traditional view of project planning based on detailed definition of activities, and control based on verification of percentage of physical development of the planned activities.

Project control using percentage of accomplished activities, in the case of high-risk, high-uncertainty, technology development projects, is not only difficult to be conducted in practice, as most of the activities are developed at the researchers' labs, but can quickly lead to an wrong perception of the project status. On the other hand, when project control is based on clearly defined (and agreed upon by the involved parties) project deliverables, not only a clear view of project status will emerge during execution, but the attention points will become more evident.

Furthermore, a monetary value will be defined to each established deliverable, and this will form the basis for the contracts involving the sponsor company and the involved research institution.

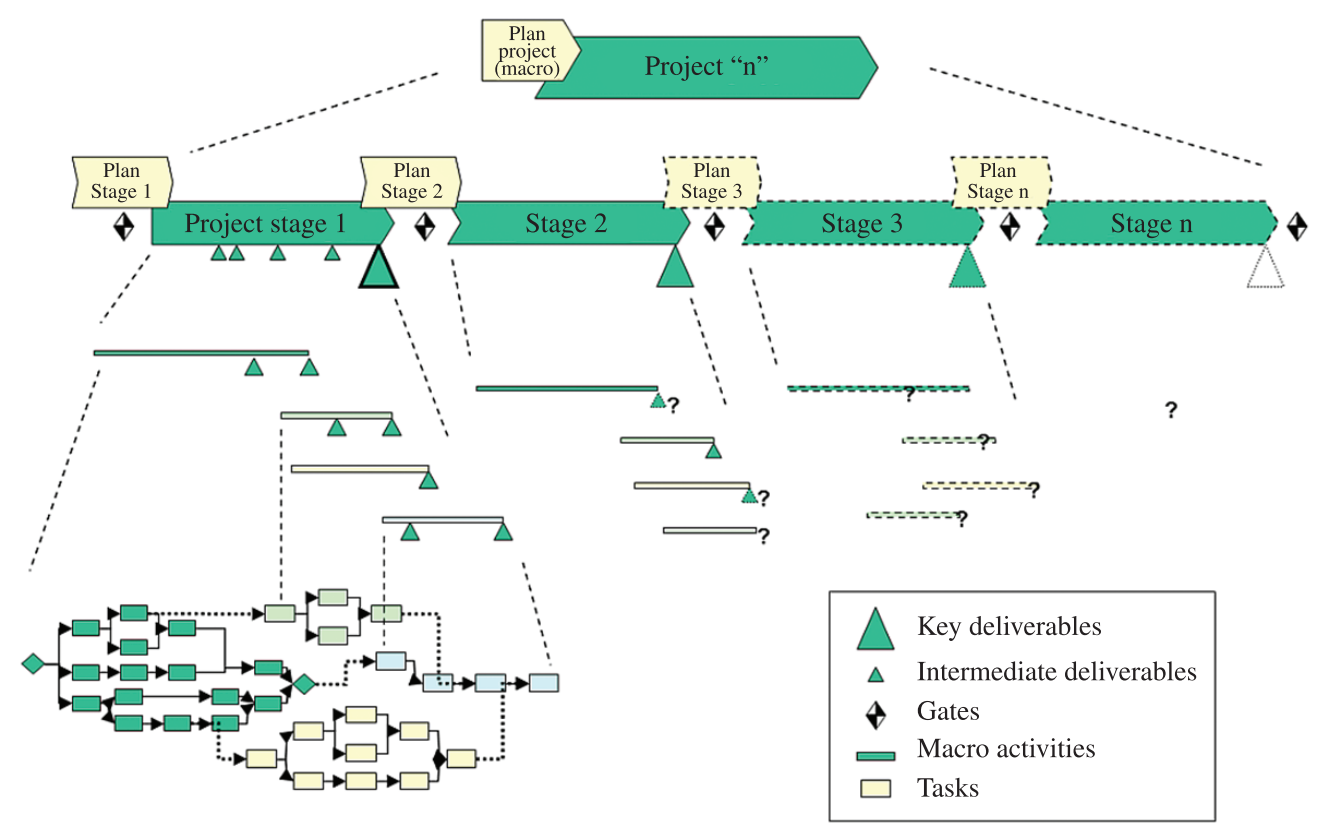

Figure 4. Wave planning applied to technology development projects. 


\subsubsection{Do not detail plan the technical work of the participant partners and teams}

In a scenery of high uncertainty, typically associated with these projects, a very frequent management mistake observed in the practice of the participant company is a trendy to try to plan to detail the work share of the other participants (including academia) and teams. This practice has many pitfalls. First, it is very unlikely to generate any positive results, as the company's management staff will not have the technical conditions and/or the time need to control the work being carried out at the researchers' laboratories. Second, too much detail (and control) will always increase the administrative costs of the project (both parties). Finally, too much control is often not well received by the executing teams, as it generally perceived as lack of confidence on their capacity's to manage their own work.

The solution that this company has learned is to build with the executing partners and teams an integrated master level plan, as described in Lesson 5.3.1, followed by the joint definition of key deliverables along the project stages, as described in Lesson 5.3.3. This will form what is called the common management and control plan, and also will be the basis for the working contract. At the detail level, on the other hand, planning and control will belong to, and will be a responsibility of, the executing partners and teams (Figure 5).

\subsubsection{Too much project planning is a wrong strategy to reduce project risk}

Directly related to the last item (Lesson 5.3.4), one reason that some of the managers who participated from this study mentioned for engaging so often in too much planning

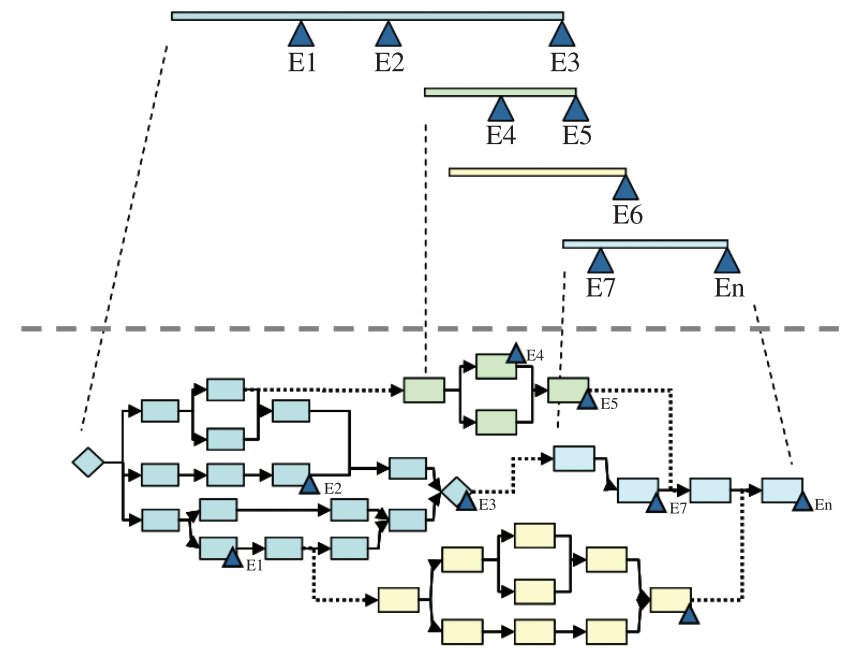

Figure 5. Distinction between the project management level and the control level (based on deliverables) and the technical level (delegated and controlled by the executing teams). at the onset of these project was as an attempt to reduce project risks. Indeed, detail planning is a very obvious and commonly advocated strategy for risk reduction, when the project object and scope is well defined (low uncertainty). As low uncertainty is not an attribute that one will find in the projects discussed in this article, too much project planning at this stage is likely to delay the project, bringing very few actual gain in risk reduction.

On the other hand, practical experience from this company shows that, at the project planning stage, project risks need to be identified, assessed and treated via definition of risk mitigation strategies and contingencies. It is only that too much project planning is not a good mitigation strategy for that purpose.

\subsubsection{The researcher leader is key in handling the bureaucratic processes at his/her institution}

If the researcher designed as the project coordinator from the academic institution side is truly motivated and involved in the project (as discussed in Lesson 5.2.1), and has a good knowledge of the internal processes and procedures at his/her own institution [and associated innovation and intellectual property organisms], then the contracting process tends to be quicker, as the interests are clearly put on the table, and the negotiation become more objective.

To understand the internal processes and specific procedures at the research institutes is therefore of fundamental importance. Nevertheless, for most cases discussed with the group of participants, the academic coordinator for the project had very limited knowledge of these processes, with a direct impact on the time delayed until the contracts were signed, as too many rounds of negotiations where typically necessary, in special to discuss aspects of intellectual property.

\subsection{Group of lessons \#4: keeping the ball rolling}

\subsubsection{Celebrate the intermediate results!}

At the studied company, celebration of the achieved intermediate targets is perceived as an excellent instrument of motivation, in special in the case of teams working physically distant from each other. This lesson is strongly bounded to Lesson 5.3.3, which suggests the adoption of intermediate deliverables as the basis for control and management of these projects. Indeed, in order to celebrate the achieved results, we need first to define and establish the intermediate and final targets for the projects, which, to a certain extent, is basically the same as defining the deliverables for the project. 


\subsubsection{Invite the academic coordinator and its team to visit the company and present the results to the internal team}

This action has a great potential to increase the motivation of both teams with the project. From one side, academic researchers will have the chance to see how the results will be, or are already being used, by the sponsor company. On the other side, the internal team will have the opportunity to clarify their needs, goals, requirements, scope of application and so on. Finally it is a unique integration event where the two teams will have a great opportunity to get to know each other.

\subsection{Group of lessons \#5: intellectual property protection}

\subsubsection{Understand the need to, and work to promote,} the publication of results by the academic team, but let it clear to all of the participants the rules and implications of academic publication for the intents of intellectual protection from the company

The publication of the research results is at the core of the academic life and work. This must be understood and even promoted by the sponsor company. On the other hand, the academic team must comprehend how the intellectual property related to the work being done is intended to be managed by the sponsor company. Non protected results are useless to generate value to the sponsor company and partner institutions and, in some cases, can even lead to monetary losses.

It should be understood, that the larger the gain to the company with the generated technology, the more tax this company will pay, and the more money will be available to institutions to conduct basic research, partnership projects, and so on. In this context, the work of what is called innovation technology organisms (NITs) becomes more important in promoting the culture of intellectual property protection in the academic institutions.

\subsection{Group of lessons \#6: making it happen: execution and control}

\subsubsection{Removing the stones from the project path}

In the studied company, the practice of visiting the actual work being performed has been demonstrated as a crucial success factor for this particular type of projects. From one side, the physical presence of the company's team members at the researchers' laboratory clearly shows to the involved academic team how important the work being conduct actually is to the sponsor company. From the other side, it an excellent opportunity to the company's team to help the academic team to solve specific technical problems or to help to decide which way to go.
In the words of one of the interviewed project managers: "I used to visit the [research team's] laboratory at least once a month. I selected the subject that the team was having more difficulties with, and helped them to solve and/or decide wich way follow. It could be, for instance, difficulties with the execution of tests, selection of materials, etc. In my view, my participation was important for two main reasons: First, in the visiting day I could finally have a full understanding of what the problem was, something that was not possible by means of phone calls, Emails or written reports. Second, in many cases the academic team was not moving ahead because they were imposing on themselves too much technical rigor on activities there were secondary to the key objectives being pursued by the project. For these cases the on-site mutual decision and alignment was fundamental to put the project back rolling, without any further delays".

\subsubsection{Pro-Active project control}

Remember to the team, normally at the begin of the month or pre-established period, what will be their next important deliverables to the project. "At the first week of the month I send a message to the whole team informing what are our next important deliverables, and who is responsible for each deliverable. This very simple measure will not only give them enough time to take the necessary actions to make things happen but also, if necessary, provides them with the opportunity to request help from the management team, if a problem to accomplish a certain deliverable is already anticipated. This way I can actively help the team to achieve our goals."

\subsection{Group of lessons \#7: communication}

\subsection{1 "When in doubt, be redundant on the essential subjects and key project alignments!" "never leave anything implied."}

Projects of this nature will normally involve people with very different backgrounds, cultures, expectations and perceptions. A clear, straightforward and unambiguous communication is an absolute must for these projects, and mentioned by almost all of the interviewed managers as a key factor for these project's success. Some common phrases are particularly "dangerous" in this context, and point to the existence of potential problems ahead: "It is implied that..."; "I think that they understood what we expect..."; "Everybody knows. There is no need for any further clarification..." To overcome this problem, exercise empathy with the team members, in special with the academic team, as these team' participants are likely not to be used to the sponsor's company culture, way of thinking and common language. If necessary, be redundant and leave no room for misunderstandings. "Let nothing implied". It 
should be noticed that this lesson can be largely enhanced by applying lesson 5.6.1, which proposes that the sponsor's team should meet the academic team as often as possible.

\subsubsection{Record all of the decisions!}

All of the decisions and follow-on tasks (including responsibilities) from meetings should be registered and saved at a common electronic location. The meetings' minutes shall be sent to all of participants.

Apart from documenting the meeting decisions and projects changes in general, the interviewed company has implemented a logbook for each ongoing project (as exemplified in Figure 6). This is a very simple document where every project event, change, problem or issue is logged, with date, actions and conclusion.

\subsection{Group of lessons \#8: project scope vs academic work scope}

\subsubsection{Establish a clear distinction line between the scope of the project and the scope of the spin-off thesis and dissertations}

It is very likely that the results from these projects will be used by the involved researchers as part of their master, doctorate or academic work. This is normal and even expected, and composes a very important motivation aspect for the involved academic teams (see also Lesson 5.5.1).

It is important to notice, however, that the degree of deepening or even the bias followed by the researcher work as part of his/her academic work may not be of immediate interest to the sponsor company, and not be part of the expected work (as established in the project scope). It is

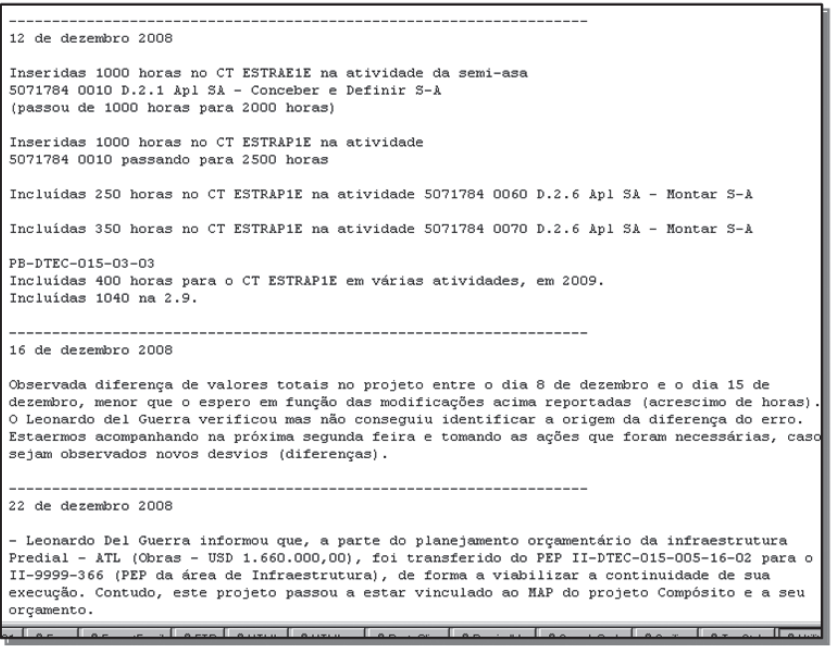

Figure 6. Keeping a simple logbook of the project is a good practice. the academic project coordinator job to keep close track of the ongoing work being carried out by his/her team, and guarantee that the frontiers are well known by all.

\subsection{2 "Keep tied to the project scope but bear in mind the learning nature of these projects... and that things can change..."}

At the same time that it is very important to the involved teams to have a clear definition of objectives, scope, schedules and planned costs, and to keep themselves engaged to achieve the proposed goals, it is also crucial to have an understanding that advanced technology development work brings at its core lots of uncertainties and opportunities. It is therefore a good idea to be open not only to correct the flow of the project as necessary, but also to exploiting new side-opportunities that may rise along the way. This can be achieved, not only by changing the project, but also by establishing a spin-off project to work on these new opportunities, at the same time that the initial project gets completed as planned.

\subsection{Group of lessons \#9: team and leadership}

\subsubsection{Academic and internal teams shall have the level of technical qualification expected to the project}

"It is not possible to perform human resources miracles in high technology projects!" It is essential that the involved team has the necessary seniority and level of technical competence compatible with the scope of the project being developed. This insight serves both to the academic team as well as the internal team (company) working in the project. Indeed, even in the cases when most of the work is supposed to be done at the academic laboratory, seniority and high level of technical proficiency from the side of the company's internal team is still requested in order to the company to have the conditions to absorb the results from the academic work.

As far as project leadership goes, attributes other than technical competence and general leadership profile appear to be necessary to the success of these projects. Among them the interviewed managers mentioned "full interest for the involved technology" and a "natural inclination for conducting exploratory, high-risk, high-uncertainty, research work". More investigation in this area needs to be done to better assess the extra leadership attributes (if any) necessary to carry these projects with success.

\subsubsection{At the sponsor company, it is a good idea to recruit the project manager from the indented organization where the technology will be applied}

A technology that is developed, but is never implemented, has a net return equals to zero. Increasing the likehood that the developed technology will be used in the future products 
of the company is one of the major preoccupations of this company's head of technology development program. An important lesson that they learned is to always recruit the project manager from organization where the technology will be used after the project is completed. This will remove, from the project onset, the "not invented here" syndrome, a major and well reported obstacle for new technologies' adoption.

\subsection{Group of lessons \#10: project management tools and methods}

5.10.1 Beware the fairytale involving all new tools and top of the crop project management methods!

"Do not be fooled into believing that a new project management tool will, by itself, solve all of your project management problems." No miracles here too. Indeed, at least $80 \%$ of these projects' challenges appear to be related to people's motivation, to keep the ball rolling, and so on, and none of these aspects are related to, or can be solved by, any tool, no matter what the vendors may say.

5.10.2 It is not possible to manage projects of this nature with generic project management methods applied to their full extend!

These projects demand proper methodology to the right level of detail, and ready to apply into practice. Questions such as "What is the minimum necessary and applicable to each areas of project management knowledge?", "What are the pre-conditions to use these methods in this scenery?" have taken a lot of the time from this company's technology development project office. It should be noticed that this is not about inventing new tools or methods. On the contrary, the experience from the participants in this study shows that there is no point in wasting time and resources inventing (or re-inventing) new tools or methods. Instead, the secret is to put things into practice. In this sense this company's technology development organization subscribes to the process and procedures proposed by the Project Management Institute, but with the extra care of simplifying each process to the right level of detail applicable to the nature of the projects being developed, a concept described in the Figure 7.

5.10.3 Make available to the participants, since the onset of the project, all of the necessary processes, procedures and templates

With this simple measure the teams will not have to waste their valuable time, for instance, discussing the way that a given report, or a test plan, should be written, and more time concentrated where their work will make the difference, that is, with the technical work.

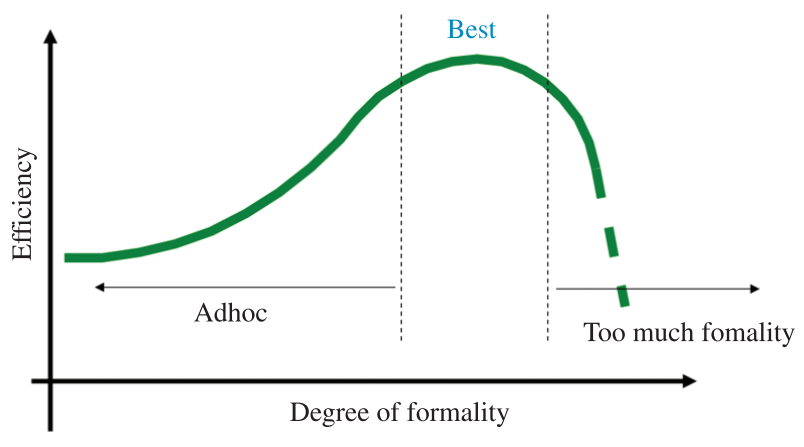

Figure 7. What is the right degree of project management process formality applicable to these projects?

\subsubsection{Make available to each new project a collaboration portal}

This measure, just as the former lesson (5.10.3), is simple and cheap to the implemented, and will save a lot of time from the teams, avoiding, for instance, the problems related to the transmission of documents, reports, plans, by Email, very often in different versions. Using the words of one of the project managers involved in the study: "In project $Z$, for instance, we had a lot of problems with the documentation that was being produced by the academic partner. The reports were sent as agreed in the contract, but, if a certain test data was requested, nobody knew for sure where the latest version of it was. A collaboration portal makes things simple and straightforward."

There are various collaboration software available in the internet, most of which free of charge, and that will demand not more than a few dozen or so of IT development hours to be deployed.

\subsection{5 "The tail should not wag the dog!"}

Project management skills, methods, abilities and tools, are indeed important to the success of these projects. Nevertheless they are not more important (nor less) than the technical activities that represent the essence of the work. That being the case, attention should never be diverted from the actual technical work being performed. Furthermore as the final result of the work is generated by the technical work the decisions of the technical experts should be always valued and respected.

\section{Conclusions}

This article presents and discusses a set of lessons learned by a large company from the Brazilian aerospace industry in the planning and execution of pre-competitive technology development projects in partnership with research institutions, as summarized by the group of project managers interviewed for this work. 
The hypothesis is that the adoption of these lessons by other companies involved in this particular type of projects has a potential to increase their probability of success in their efforts to generate results when developing projects in partnership with academia.

We should notice that the results were drawn from the practical experience of one company only, and is based on the interviews with project managers involved in these projects for more than 14 years. Further investigative research with other companies and sectors is advised in order to validate each of the lessons discussed in this article, an important step towards transforming lessons into best practice.

\section{Acknowledgements}

The following employees from the company contributed with information and/or stories that formed the basis for the present work: Glauco Humberto Gomes, Andre Gonzales, José Ricardo Patelli Jr., Jose Ricardo Parizi Negrão, Leonardo Bastos de Toledo, Rafael de Marco e Melo, Raquel Rocha Mancilha Simomura, Valeriano Boni Neto e Wander Stange Menchik.

\section{References}

AJAMIAN, G. M.; KOEN, P. A. Technology Stage-GateTM: a structured process for mangaging high-risk new technology projects. In: BELLIVEAU, P.; GRIFIN, A.; SOMERMEYER, S. The PDMA tookbok: for new product development. New York: John Wiley \& Sons, Inc., 2002. p. 267-295.

ALVES, H. A. Plataforma de apoio à decisão na inserção de tecnologias em produtos aeronáuticos. 2009. Dissertação (Mestrado em Engenharia Aeronautica e Mecanica, Sistemas Aeroespaciais e Mecatronica)-Instituto Tecnologico de Aeronautica, São José dos Campos, 2009.

ARAUJO, C. S.; CRUZ, J. L. A view of the practice of Integrated Product Development at EMBRAER. In: SEMINÁRIO INTERNACIONAL DE ALTA TECNOLOGIA: INOVAÇÕES TECNOLÓGICAS NO DESENVOLVIMENTO DO PRODUTO, 5., 2000, Piracicaba. Anais... Piracicaba: Universidade Metodista Paulista, 2000.

BALAGUER, D. et al. R\&D Public Policies for the Aeronautical Industry: an empirical comparative analysis between Brazil, USA and Europe. In: INTERNATIONAL
SCHUMPETER SOCIETY CONFERENCE, 2008, Rio de Janeiro. Proceedings... Rio de Janeiro, 2008.

CAETANO, M. et al. Open Innovation and Technology Development Process: The Gap on Partnership Adoption from a case Study Perspective. Product: Management \& Development, v. 9, n. 2, p. 111-120, 2011.

COOPER, R. G. Managing Technology Development Projects. IEEE Engineering Management Review, v. 35, n. 1, 2007. http://dx.doi.org/10.1109/EMR.2007.329141

COOPER, R. G. Perspective: The stage-gate ${ }^{\circledR}$ idea-to-launch process-update, what's new, and nexgen system. Journal of Product Innovation Management, v. 25, p. 213-232, 2008. http://dx.doi.org/10.1111/j.1540-5885.2008.00296.x

CHESBROUGH, H. W. The era of open innovation. Mit Sloan Management Review, v. 44, n. 3, 2003.

DINSMORE, P. AMA Handbook of Project Management. AMACOM Books, 1993.

FRAME, D. Managing Projects in Organizations: how to make the best use of time, techniques and people. Ed. Jossey Bass, 1995.

KERZNER, H. Gestão de Projetos: as melhores práticas. Porto Alegre: Bookman, 2002.

MORRIS, P.; PINTO, J. K. The Wiley Guide to Project Organization and Project Management Competencies. Wiley, 2007.

PAAP, J. Technology Scouting to Accelerate Innovation. In: MANAGEMENT ROUNDTABLE, EXECUTIVE WORKSHOP, 2006, Cambridge. Proceedings... Cambridge, 2006.

PROJECT MANAGEMENT INSTITUTE - PMI. Um Guia do Conhecimento em Gerenciamento de Projetos (Guia PMBOK). 4. ed. PMI, 2008.

SANTOS, J. A.; CARVALHO, H. G. Referencial Brasileiro de Competências em Gerenciamento de Projetos. Curitiba: Associação Brasileira de Gerenciamento de Projetos, 2006.

SHENHAR, A. J.; WIDEMAN, R. M. Optimizing project success by matching management style to project type. PM World Today, PMForum, 2000. Disponível em: <http:// www.pmforum.org/library/papers/2000/PM_Style\&Scss. pdf>. Acesso em: 15 fev. 2006. 